\title{
A Cartografia da Ação na Escola e a Pesca em São Gonçalo (rj)
}

\author{
Ivy Schipper - \\ LASTRO Laboratório da Conjuntura Social: \\ Tecnologia e Território
}

\section{Resumo}

A Cartografia da ação é uma metodologia de pesquisa desenvolvida para a observação dos traços conjunturais apontados por mudanças na ação social em contextos metropolitanos. O objetivo geral desta experiência foi trazer para a sala de aula do ensino público fundamental o contexto da luta e os objetivos dos pescadores artesanais de São Gonçalo, e sua representação pela FEPERJ. Esta luta tem por objetivo o enfrentamento de perversas conseqüências trazidas pela expansão da atividade petrolífera na Baía de Guanabara. $\mathrm{Na}$ experiência em foco (realizada no segundo semestre de 2009) trabalhamos com alunos de $4^{a}$ série $-5^{\circ}$ ano com idades de 11 anos em média. Nesta oportunidade a leitura ativa do território foi realizada em três sessões (entre 30 e novembro e 10 de dezembro).

Palavras-chave: Ação social ; rede estadual de Ensino Público ; metodologia ; simbolização.

\section{Abstract}

Action's Cartography is a research methodology developed to the observation of conjunctural traces pointed out by changes in social action at the metropolitan context. The general aim of the experience here described was to bring to the state public school system in São Gonçalo city the fight and the claims of the handmade fishermen and its representation by FEPERJ ( the Rio de Janeiro State Federation of Fishermen). This fight aims to face perverse consequences brought by the expansion of Oil activity in Guanabara Bay. In the mentioned experience ( performed in the second semester of 2009) we worked with students from the 4th class ( 5 th year), with average age of 11 year. At this time it took three sessions between November 30 th and December 10 th ,2009 to make the territory active reading.

Key-words: Social action; state public school system; methodology; symbolization.

\section{Introdução}

Pretendemos neste relato registrar a segunda experiência de desenvolvimento da metodologia de leitura da ação social através da construção de mapas na escola (rede de ensino público estadual) que reuniu parte das equipes do LABORATÓRIO DA CONJUNTURA SOCIAL: TECNOLOGIA E TERRITÓRIO - LASTRO - IPPUR / UFRJ e do LABORATÓRIO DE ESTUDOS DO LESTE METROPOLITANO - LEME - FFP / UERJ 
(São Gonçalo) nas pessoas de Ivy Schipper; e Paola Machado de Oliveira e Luis de Souza $\mathrm{Jr}$, respectivamente.

A Cartografia da ação ${ }^{1}$ é uma metodologia de pesquisa desenvolvida inicialmente para a observação dos traços conjunturais apontados por mudanças na ação social em contextos metropolitanos. Desde 1999 praticada no LASTRO, inclui uma leitura inicial da realidade através da reunião de registros da grande imprensa sobre protestos com visibilidade nos espaços públicos; a sistematização dos dados coletados através do Banco de Ações e Processos Sociais (BAPS); o mapeamento dos dados relativos às condições de vida no espaço urbano, e o possível aprofundamento da investigação através de técnicas qualitativas de pesquisa social.

Consideramos que a observação sistemática dos sujeitos sociais e tipos de ação (além das demais variáveis observadas nos registros do BAPS) apóiam a valorização da leitura ativa do território. Acreditamos que formas alternativas de produção da compreensão do território, compartilhadas com novas gerações de estudantes e trabalhadores são um precioso meio de intercâmbio de diferentes tipos de saber. Pois, para nós, os tipos de leitura de espaço realizado em mapas da geografia e apresentado em publicações acadêmicas em geral não tratam de representar o movimento da sociedade no território (COSTA, 2003), mas sim um território inerte, correspondente à cristalização da ação hegemônica, cujos interesses se afirmam na manutenção de mecanismos geradores de desigualdades absurdas.

Neste sentido, a partir do diálogo entre ciências sociais, educação e saberes culturais, a Cartografia da Ação se investe na possibilidade de renovação crítica da leitura da ação social, através da valorização do "território usado" (SANTOS, 1999a). Seguimos com Milton Santos (1994b) compreendendo que o espaço geográfico, como instância concreta e verdadeira da vida material, contém a totalidade dos atores que aí subsistem, com ênfase dada à presença do "homem lento", aquele que por não dispor dos acessos e meios de usufruto da aceleração contemporânea em seu favor, faz de sua experiência vivida e sua corporeidade os seus meios de socialização na cidade.

\section{Objetivo geral}

O objetivo geral desta experiência foi trazer para a sala de aula do ensino público fundamental o contexto da luta e os objetivos dos pescadores artesanais de São Gonçalo. Esta luta tem por objetivo o enfrentamento de perversas conseqüências trazidas pela expansão da atividade petrolífera na Baía de Guanabara, altamente nocivo ao ecossistema local e aos modos de vida e trabalho tradicionais. Assim, diante da brutal retração da pesca artesanal, esta luta já logrou a conquista perante a Petrobrás o financiamento, para a execução pelos pescadores, do projeto Baía Limpa, que tem por objetivo a realização da coleta de dejetos, que deterioram aquelas condições e modos de vida marítimos. Neste sentido, através do LEME vem sendo oferecido aos pescadores artesanais apoio científico nos procedimentos de organização da coleta de lixo e análise dos resíduos sólidos coletados. Ainda, em conjunção de esforços nossos laboratórios procuram não apenas evidenciar aos alunos a destruição do ambiente marinho e da 


\section{REVISTA TAMOIOS}

cultura local, mas também resgatar vínculos locais e dar visibilidade à organização e às ações de resistência contraposta pelos pescadores artesanais.

\section{Referenciamento conceitual}

Diante do quadro de transformações urbanas do atual período histórico, quando acontecem investimentos na apreensão do tecido social, os conhecimentos alcançados pelos estudos científicos retornam rapidamente ao exercício da política e da economia. A opção conceitual pela perspectiva do vínculo social aponta para um aprendizado mais profundo da organização social, e para a valorização dos gestos (RIBEIRO, 2005, p.411) que, apesar da aceleração e da fragmentação da vida na metrópole, asseguram a continuidade de uma sociabilidade fundamental à vida em grupo.

Neste sentido, optamos por uma prática que, mesmo desobedecendo alguma exigência atribuída pela geografia à cartografia, favorecesse a possibilidade de compartilhamento com os alunos não apenas da produção de mapas, mas também do espaço de representação da ação social estudada, com a consideração e a representação da ação das crianças, na forma como esta é percebida pelos alunos.

Para isto, nos apoiamos nas reflexões de Santos (1991c) que, postulando a necessidade de reconfiguração da sociologia do direito, dá relevância ao espaço geográfico como elemento analítico indispensável, e explicita alguns dos principais mecanismos de representação e distorção da realidade pela cartografia, como meio simbólico e analógico adequado para a compreensão científica da realidade contemporânea.

\section{A ação social e seu posicionamento no presente}

A ação social que buscamos apreender diz respeito ao posicionamento efetivo de grupos socialmente desfavorecidos no espaço público diante de problemáticas condições materiais e simbólicas de existência. Neste sentido, importa para nós que a ação social seja autônoma, independendo de vínculos com atores poderosos ou até hegemônicos, e espontânea, no sentido de que há um reconhecimento da gravidade da situação e uma tomada de responsabilidade na iniciativa de se manifestar contra algo e contra alguém. Esta espontaneidade tem ainda grandes implicações no que se refere ao fato de provocar um rompimento nas rotinas convencionais do cotidiano, trazendo para o presente a concretude da vontade de mudança. Nesta concretude, valorizamos a imanência da visibilidade colada à apropriação e coletivização (mesmo que momentânea) de espaços públicos ou privados, e ainda, a potente transcendência destas ações, expressivas da criatividade com que os grupos populares se manifestam.

\section{A representação cartográfica e a ação social}

Os procedimentos cartográficos descritos por Santos (1991c) correspondem ao uso da escala, da projeção e da simbolização. Em nosso uso experimental, verificamos uma 
distorção controlada no uso da escala (esclarecida mais adiante) devido à adequação que fizemos em relação ao centro da projeção.

O mecanismo da escala regula a relação entre as distâncias no terreno e a correspondente distância no mapa. Implica em um grau de pormenorização na representação. As representações de grande escala permitem a visualização de espaços reduzidos, com elevado grau de pormenorização (detalhamento). A pequena e a média escala favorecem a observação de posições relativas entre os elementos do espaço representados (referenciando uns em relação aos outros) ao longo de significativas extensões de território. "Porque medeia entre intenção e ação, o mecanismo da escala também se aplica à ação social" (SANTOS, 1991c, p.65), vide as utilizações da escala nas representações de poder.

Assim, se em um mapa com escala apropriada para a representação da ação dos pescadores no entorno metropolitano da Baía de Guanabara introduzimos a diversidade de um tipo de ação (das crianças) representada em apenas um município, acreditamos estarmos potencializando a expressividade desta ação na representação.

A projeção na cartografia se refere ao procedimento que favorece a representação da superfície curva da terra na superfície plana dos mapas. Porém, isto só é possível na medida em que são distorcidas ou as formas, ângulos e direções ou as áreas que estão sendo representadas. As projeções conformais preservam a área e distorcem formas ângulos e direções, e as projeções equivalentes vice-e-versa. Assim, é impossível obter o mesmo grau de exatidão na representação de diferentes atributos. Considerando ainda que a escolha do tipo e do grau de distorção obedece ao intuito da representação e à versatilidade (inclusive ideológica) do cartógrafo.

A projeção se caracteriza ainda por dispor a representação cartográfica de um centro, ponto fixo crucial relacionado ao período histórico da representação ou à tradição cultural, em volta do qual se dispersam organizadamente os restantes espaços. Assim, relações centro-periferia são observadas nos mapas cartográficos e nos mapas mentais, que são imagens visuais cognitivas do mundo que nos rodeia, onde a percepção cognitiva do espaço privilegia a vizinhança e o familiar (SANTOS, 1991c.,p.66).

$\mathrm{Na}$ medida em que na representação que construímos procuramos articular dois tipos distintos de ação (a de pescadores e a de crianças), trouxemos analiticamente para o núcleo desta aproximação o estabelecimento de responsabilidades como nexo central de identidade (o centro de nossa projeção) entre estes dois sujeitos, o que possibilitou a representação conjunta destas ações. Enquanto que para os pescadores, existe uma responsabilidade manifesta em sua mobilização e na interrupção do cotidiano de trabalho e de rotinas no centro da cidade, para as crianças, vale a responsabilidade atribuída aos irmãos mais velhos pelos pais (quando se ausentam) no cuidado com os irmãos mais novos $^{2}$.

Fazendo uso da distinção enunciada por Keates (1982, apud SANTOS, 1991C, p. 66) entre sinais icônicos e sinais convencionais, Boaventura de Souza Santos recorre à semiótica para considerar que os sinais icônicos estabelecem uma relação de semelhança 
com a realidade representada, enquanto os sinais convencionais caracterizam-se por usar de maneira arbitrária linhas (limites, fronteiras), círculos (para representar cidades, tamanhas de população) e etc.

Para o autor, a simbolização é o lado visível das representações da realidade. Através de símbolos gráficos se assinalam os elementos e as características da realidade espacial selecionados. É o procedimento técnico mais complexo, pois que sua execução é condicionada tanto pelo tipo de escala, como pelo tipo de projeção adotado. No caso descrito por Boaventura, de estudo de simbolização jurídica da realidade, o autor recorre às contribuições da semiótica, além da retórica, da antropologia cultural e da crítica literária.

Em nosso caso, na medida em que iniciamos a leitura da realidade a partir de desenhos dos alunos, temos que ter em mente que no caso destes desenhos, procuramos reunir informações visualmente representadas por crianças - os alunos, e selecioná-las para que os alunos pudessem adaptá-las a um tamanho adequado para sua inserção no mapa. No caso da representação simbólica da ação dos pescadores, a exibição de uma foto jornalística da barqueta permitiu uma informação prévia do imaginário visual dos alunos, posteriormente sendo solicitada sua adequação às quadrículas com pequenos desenhos, transpostas ao mapa.

\section{A prática}

\section{Informações motivacionais da experiência}

$\mathrm{Na}$ experiência em foco (realizada no segundo semestre de 2009) trabalhamos com alunos de $4^{\mathrm{a}}$ série $-^{\circ}$ ano com idades de 11 anos em média (variando de 10 até 14 anos). Aproveitamos a oportunidade de lidar com uma classe e um nível de ensino que ainda não tem em seu currículo uma grade com a diferenciação convencional das disciplinas que compõe o conhecimento social (história, geografia, sociologia, etc.) e que estão considerados pela Faculdade na formação dos professores de geografia ainda experimentalmente. Portanto, além de nos inserirmos como projeto acadêmico no cotidiano escolar ${ }^{3}$, nesta oportunidade a experiência foi realizada em três sessões (entre 30 e novembro e 10 de dezembro).

Experimentamos logo no momento inicial desse encontro considerar a compreensão prévia que os alunos traziam sobre a noção de ação. (As contribuições apontaram no sentido dessa acepção como conteúdo dos filmes de violência). Desenvolvemos ainda o trabalho prévio com imagens desenhadas por eles a respeito de sua percepção e experiência em relação à composição do espaço da cidade e ao uso que fazem deste.

\section{Breve descrição da escola}

A escola fica instalada em um terreno cedido pelo antigo líder da colônia de pescadores do bairro, cujo nome - Carlos Maia - foi adotado como nome da escola. Atende alunos do bairro e seu entorno possuindo seis salas de aula, uma cozinha, um 


\section{REVISTA TAMOIOS}

refeitório, dois banheiros para alunos e um pátio central além dos recintos da diretoria, coordenação e secretaria.

\section{Trabalhos prévios}

O trabalho propriamente orientado para a prática junto aos alunos foi precedido por uma visita à sede da Federação dos Pescadores do Estado do Rio de Janeiro - FEPERJ, com intuito de recuperar registros sobre suas próprias ações. Nesta visita, obtivemos através da secretaria do órgão duas matérias recortadas de jornal a respeito das lutas dos pescadores relativas à atividade na Baía de Guanabara ("Petrobrás ainda não pagou pescadores" de autoria de Denise Almeida publicada no Jornal do Brasil em 02 / 10 / 2007 , e "Barqueata cruza águas da Baía de Guanabara para cobrar soluções", autoria de Leon Corrêa, sem fonte e sem data, o que nos levou a considerar como fonte nosso próprio sujeito da ação, a FEPERJ), além de publicações especializadas (revistas "Pesca e mar" e "Linha verde").

Posteriormente houve uma etapa de socialização destes materiais reunidos, a definição da dinâmica a ser aplicada durante a experiência, e a construção prévia de uma base cartográfica "muda" a ser fornecida aos alunos no momento da construção do mapa da ação.

\section{Materiais utilizados}

Por ser oferecida como um projeto dentro da grade convencional dos estudos semanais, a Cartografia da Ação demanda o uso de materiais específicos para a sua realização. Estes materiais são repassados aos alunos dentro de uma pasta que chamamos de "leva e traz" com a qual intercambiamos alguns materiais impressos com os alunos: cópia da notícia da barqueata, glossário, ficha de classificação, mapa da poluição e assoreamento na Baía de Guanabara, mapa de bairros de São Gonçalo, mapa da região metropolitana do Rio de Janeiro. A escola disponibilizou-nos também seus equipamentos digitais (câmera fotográfica, laptop, data show). Para as sessões de desenho disponibilizamos aos alunos folhas ofício, caixas de lápis de cor e caixas de canetas hidrocor para as representações em forma de desenho.

\section{Uso de recursos digitais no intercâmbio de informações e representações com os alunos}

Recorremos à utilização de equipamento digital em sala de aula (data show / laptop) para através da observação de mapas conversarmos com os alunos sobre a percepção da cidade em mapas, para introduzirmos então a problemática da baía de Guanabara tendo como referência a ação dos pescadores e o intercâmbio de informações com os alunos: seu conhecimento sobre os vários bairros da cidade, destacando os bairros de casa e da escola. 

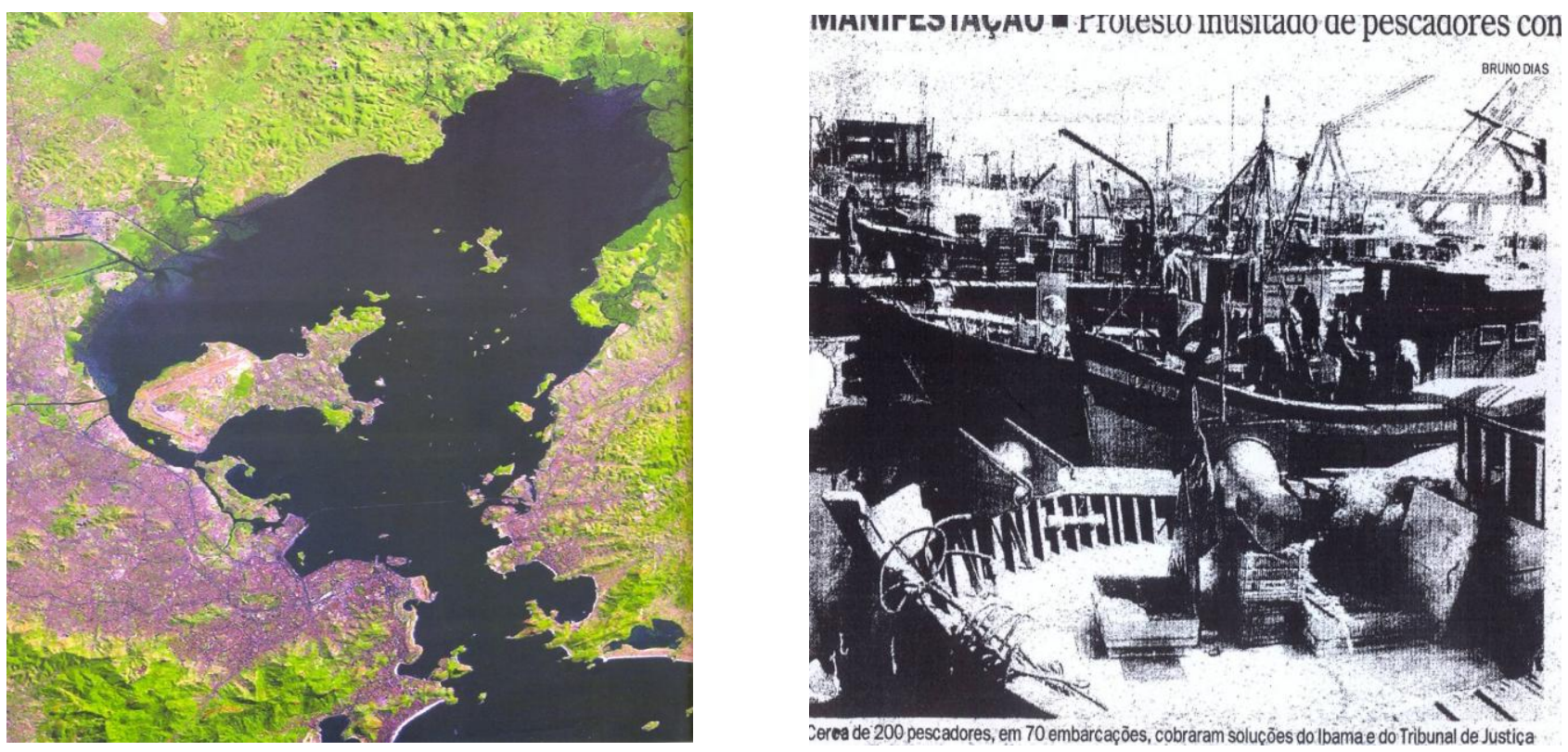

Fonte: Imagens extraídas do projeto Territórios da Juventude - Experiência: "A cartografia da ação na escola e a pesca em São Gonçalo"

Finalmente introduzimos através da exposição e leitura da notícia de jornal, a luta e as problemáticas colocadas pela ação dos pescadores, para que os alunos pudessem representar em desenhos as informações debatidas.

\section{Leitura e classificação da notícia sobre a ação dos pescadores}

Para realizarmos uma primeira aproximação da realidade de enfrentamento de problemas pelos pescadores artesanais organizados, procedemos na sala de aula uma leitura onde a cada parágrafo lido procurávamos destacar os componentes da ação e debater os conteúdos associados ao enfrentamento em foco. 


\section{REVISTA TAMOIOS}

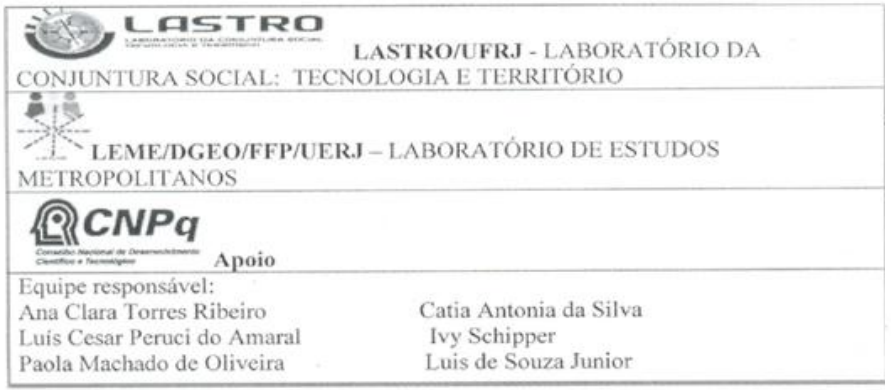

A CARTOGRAFIA DA AÇÃo E A PESCA EM SÃo GONÇALO

FICHA DE CLASSIFICAÇÃO

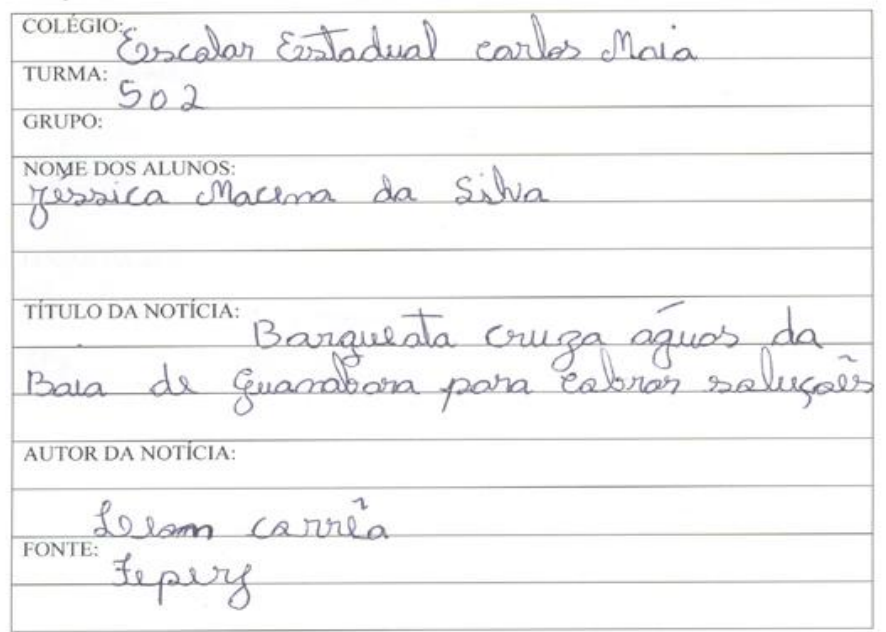

A CARTOGRAFIA DA AÇÃO E A PESCA EM SÃO GONÇALO

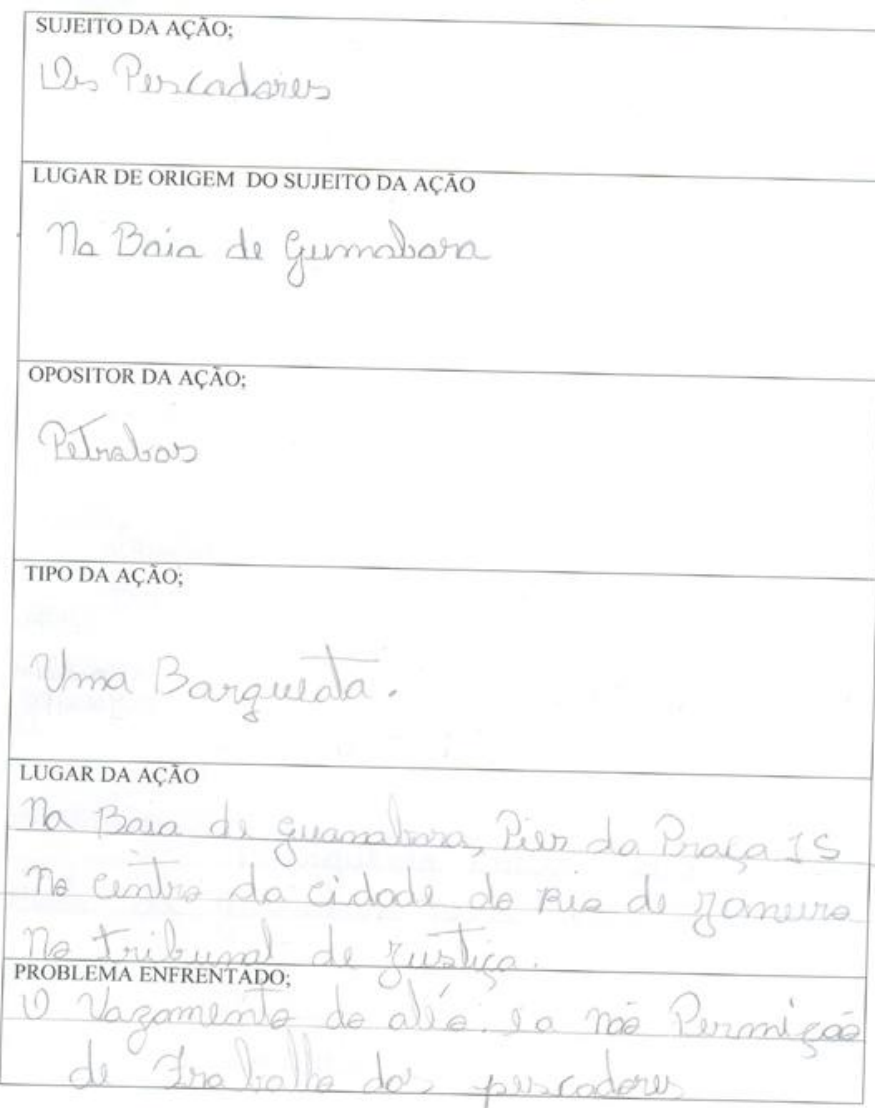

Fichas de classificação. Fonte: Experiência "A cartografia da ação na escola e a pesca em São Gonçalo"

Posteriormente, realizamos o preenchimento da ficha de classificação. Os alunos participaram ativamente neste momento. Como esta atividade ocorreu em conjunto com toda a turma, os campos da ficha de classificação eram debatidos e respondidos oralmente e por escrito nestas.

\section{Sessão de desenhos}

As sessões de desenho, na medida em que foram propostas aos alunos com antecedência em relação aos esclarecimentos mais conceituais da experiência, assumiram um caráter muito relaxante em relação ás disciplinas da escolaridade.

Da mesma forma que podemos começar discutindo em sala de aula algum termo partindo da percepção que os alunos trazem por si próprios, os desenhos podem ser propostos com este sentido de introdução de um assunto. De acordo com Pontuschka ET $\mathrm{AL}$ (2007) os desenhos espontâneos das crianças representam o seu mundo próximo, expressivo da capacidade cognitiva, faixa etária, nível de informação e condições socioeconômicas. Em nosso caso, ao invés de surgirem como sínteses verbais de suas 


\section{REVISTA TAMOIOS}

experiências prévias, estes registros desenhados surgem como uma composição de elementos icônicos, fonte para simbolizações gráficas a respeito das informações que queremos intercambiar com os alunos. Para Ostrower ${ }^{4}$ (1990, p.93), com a préadolescência, inicia-se uma nova etapa no desenvolvimento infantil, com implicações na criatividade e no uso da linguagem visual. Começam a surgir nas representações da criança, orientações e referências que não se centram mais apenas na sua pessoa, já que são externas ao mundo infantil. A criança pode distinguir sua visão da de outros, o que envolve a individuação e a descoberta de suas potencialidades.

Foram realizadas duas atividades com desenhos. A primeira atividade, aplicada logo no início da experiência, visou reunir esta compreensão prévia que os alunos têm de cidade, e também um material que pôde nos informar a respeito do que sejam indícios de ação autônoma das crianças.

A atividade inicial foi dividida em duas propostas. A primeira onde a proposta era desenhar "o que é a cidade de São Gonçalo para as crianças", surgiu um tipo de cidade que é composta pela representação geral de lugares como a escola, a casa de amigas, campos de futebol, a praça, a rua, e ainda os sinais de trânsito, as bicicletas e os automóveis, aviões, casas com quintal, lan house, shopping, mercado, farmácia, hospital, posto de saúde, posto de gasolina, igreja, a UERJ, ou seja, vários exemplos de setores de atividades e serviços urbanos.
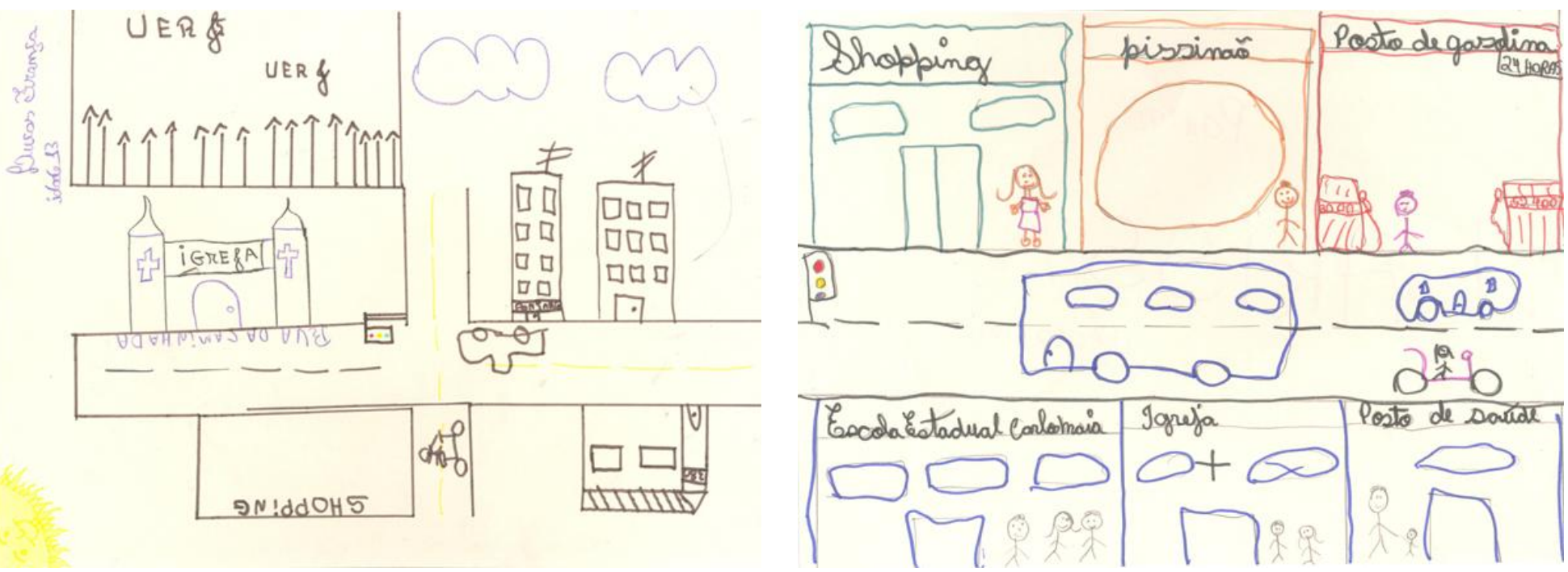

O que é a cidade para as crianças. Fonte: Experiência "A cartografia da ação na escola e a pesca em São Gonçalo" 
A segunda proposta, tematizada pelo enunciado "qual o lugar que você vai e faz coisas que você gosta quando os adultos não estão por perto", provocou a expressão de um imaginário contendo lugares com representações do tipo "Pica pau" (nome de comunidade) dispondo de uma variedade de casas, barracas, lugares simples sem a presença de ruas asfaltadas e carros, casas com quintais, alguma vegetação, e espaços coletivos. Surgiu também um tipo de "lugar marítimo", com imagens lúdicas de uma animada vida costeira: intensa pesca pessoas sendo transportadas em barcos com bandeiras, pára-quedistas povoando os ares, pessoas brincando na beira de ilhas, etc..

A segunda atividade com desenhos teve um caráter mais livre, foi proposta para ser feita em casa, a partir de uma escolha dos alunos dentre os termos existentes no glossário. Neste sentido, esta segunda atividade com desenhos buscou associar esta sondagem de elementos icônicos registrados pelos alunos aos termos do glossário.
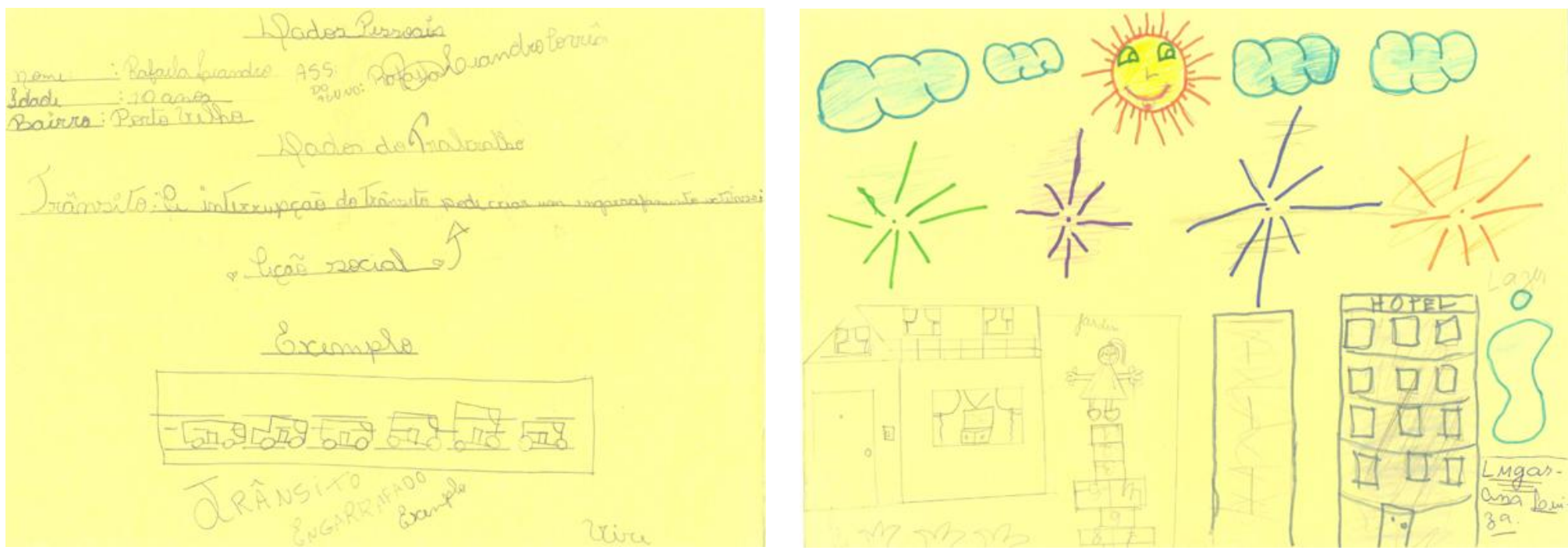

Desenhos sobre os termos do glossário "ação social" e "lugar". Fonte: Experiência " $A$ cartografia da ação na escola e a pesca em São Gonçalo"

\section{Compartilhando representações}

O princípio de observar como os alunos representam sua percepção e ação na cidade possibilitou fazer do mapa da ação em construção um âmbito de compartilhamento do espaço contendo a representação da ação das crianças junto com a representação da ação dos pescadores. Se, de acordo com Arango e Rendón (2008) ${ }^{5}$, "a antropologia visual não almeja para os estudos sobre a memória um texto acabado, ela abre um espaço para a interação das representações em mãos: as do investigador e as do seu investigado", a experiência de aproximação com o mundo das crianças se tornou um passo para a consolidação do registro do intercâmbio de conhecimentos com os alunos. Porque paralelamente a isto, estes registros tratam de visualizar a memória e a imaginação que os alunos, pequenos jovens, carregam de seu presente. 
Além disto, pelas incertezas que enfrentamos na maneira de conceber o texto e as legendas no mapa, acreditamos que, como interlocutores, nós, os pesquisadores, tivemos também destacado o registro de nossa participação neste processo experimental de pesquisa. Diante da realização desta proposta, nos defrontamos com pelo menos três tipos controlados de distorção. O primeiro foi à distorção do mecanismo de escala de redução cartográfica para podermos reunir a ação das crianças de São Gonçalo em um mapa do entorno da baía de Guanabara e da ação dos pescadores. O segundo foi simbolizar sujeitos e opositores indiferenciados de suas ações numa categorização composta: pescadores +barqueata; Petrobrás + vazamento de óleo; Tribunal de justiça + não cumprimento de indenizações pela Petrobrás, e IBAMA + cassação de licença de pescadores. Finalmente intitulamos o mapa com dois nomes: a) Mapa de São Gonçalo, da baía de Guanabara e de todos nós; e b) Cartograma: A ação dos pescadores e das crianças de São Gonçalo: compartilhando representações; e ainda c) a adoção da expressão mapa de todos nós como um apelido, para o mapa.

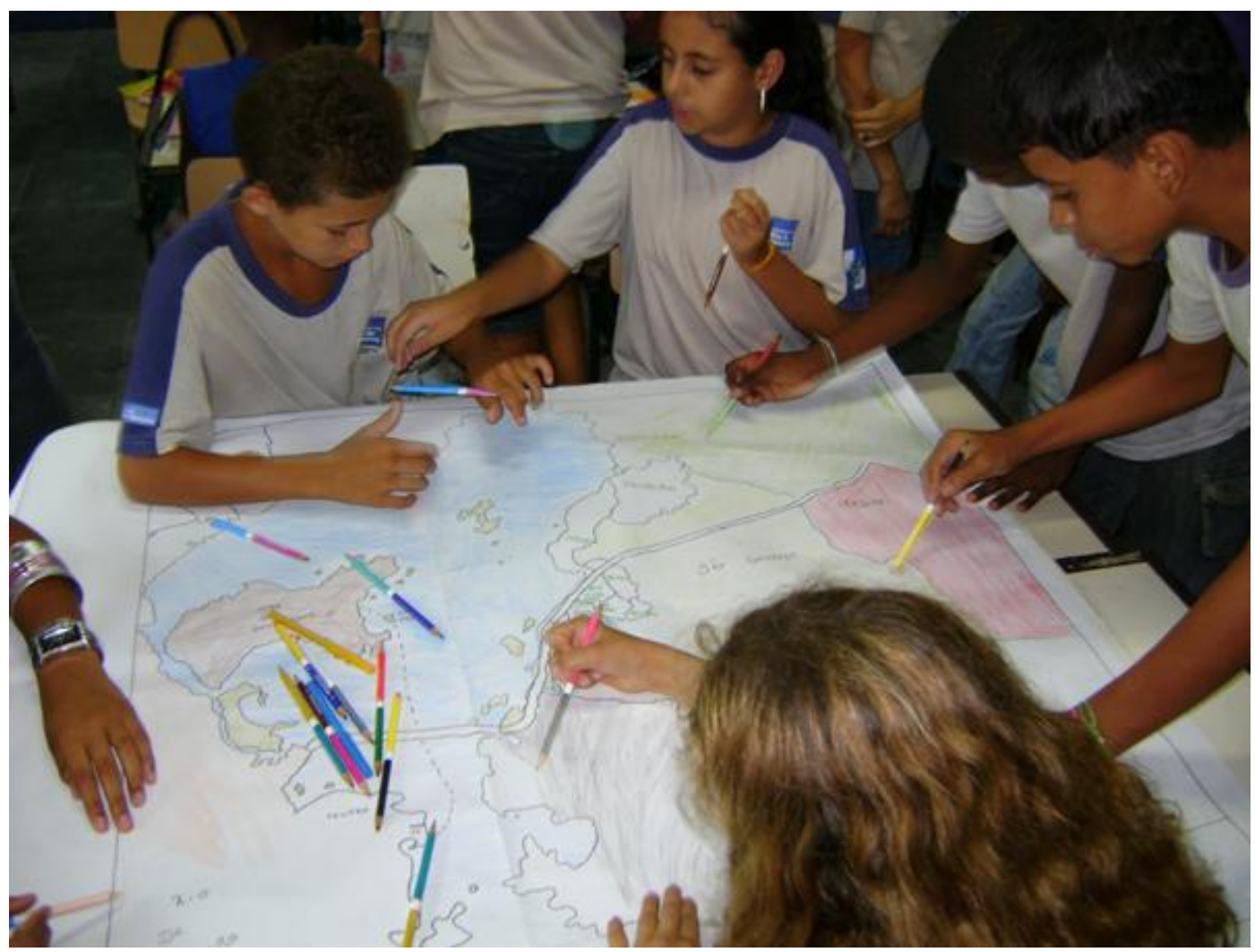

Pintando o mapa. Fonte: Experiência - "A cartografia da ação na escola e a pesca em São Gonçalo"

\section{Avaliação da experiência pelos alunos}

Como atividade de encerramento solicitou-se aos alunos que escrevessem um pouco a respeito do que eles experimentaram durante as sessões, e pedimos que sugerissem nomes para o mapa também. Houve uma série de registros positivos a nosso respeito. Além disto, fizeram alusões às atividades de desenho especificando os itens que eles 


\section{REVISTA TAMOIOS}

destacaram ao retratar a cidade e os lugares que eles gostam de ir; o aprendizado sobre os pescadores que realizaram a barqueata, e também sobre o uso do mapa da baía de Guanabara. Finalmente, a composição do nome do mapa surgiu da consideração de três sugestões diferentes.

\section{Resultados}

Os alunos procederam coletivamente à construção de elementos básicos do mapa; enunciaram relações próprias de proximidade com seu espaço vivido; compartilharam a leitura em classe; acompanharam a utilização de equipamentos digitais; vivenciaram o debate sobre problemáticas recentes e presentes sobre as condições de trabalho dos pescadores em São Gonçalo; efetuaram a criação de símbolos e efetivaram a transposição destes para o mapa da ação, consolidando o auto-reconhecimento no produto de seu trabalho. Criaram ainda registros escritos a respeito do processo e forneceram subsídios para a composição do título do mapa.

Assim, acreditamos que o sentido de compartilhamento da experiência ficou evidenciado no mapa, onde combinamos expressões nossas e dos alunos. Acreditamos ter reunido três classes de sujeito: os alunos como sujeitos do conhecimento e como potenciais sujeito da ação; os pescadores como efetivos sujeitos da ação, nexo vivo com o presente e a necessidade de transformação social; e nós, pesquisadores: sujeitos do reconhecimento da diversidade e de nossos próprios reposicionamentos.

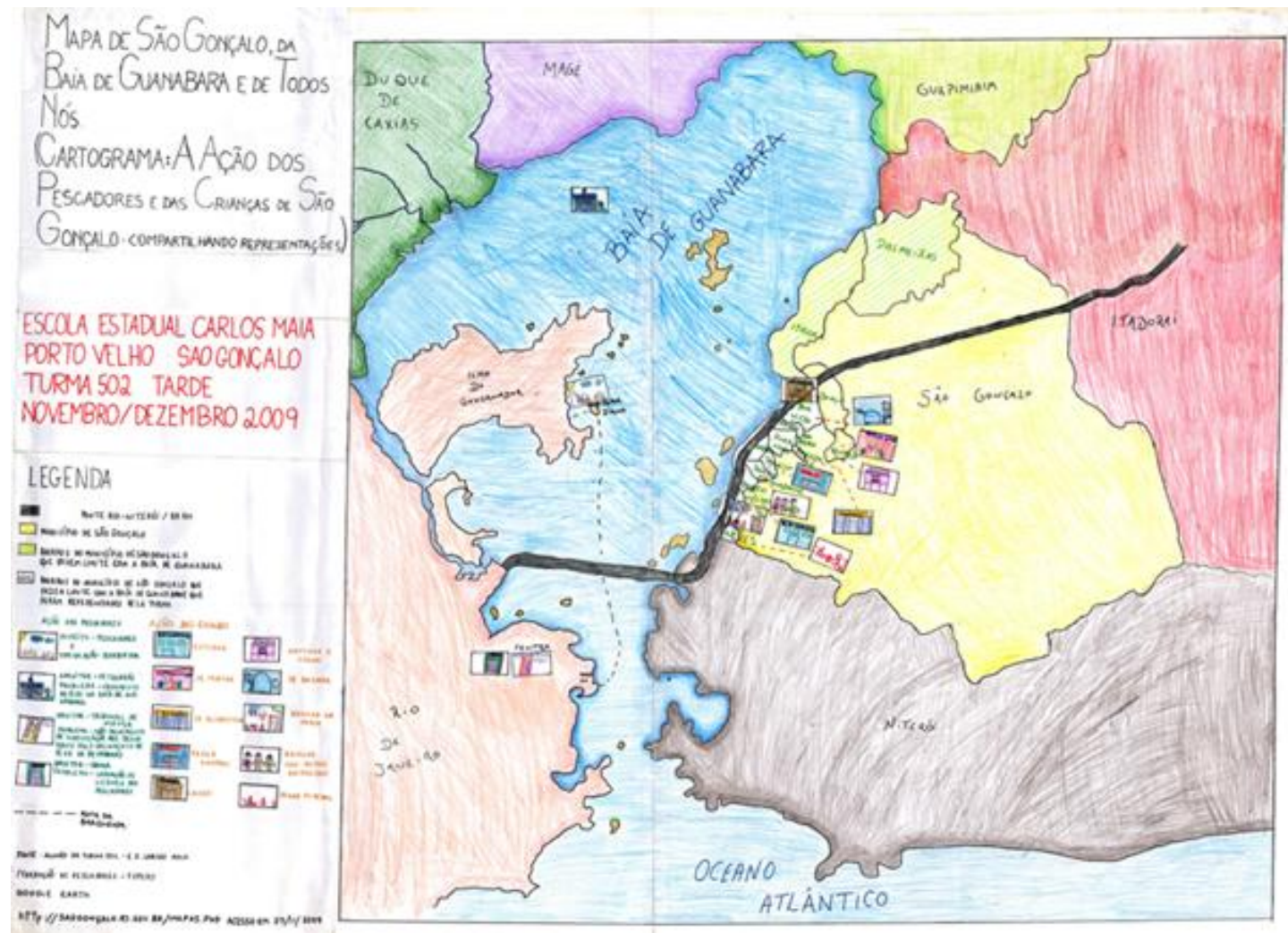

Mapa de todos nós. Fonte: Experiência - "A cartografia da ação na escola e a pesca em São Gonçalo" 
Obs: Por não ter sido o objetivo do exercício o tratamento detalhado dos municípios limítrofes de São Gonçalo, não foi definida no mapa a fronteira que separa os município de Niterói e Maricá.

\section{NOTAS}

1 RIBEIRO, A.C.T. Vínculo social: cartografia da ação em contextos metropolitanos. Projeto de pesquisa. Rio de Janeiro: LASTRO-IPPUR/UFRJ, CNPq/FAPERJ, 2007.

${ }^{2}$ Reiteramos o valor desta aproximação, pelo fato de ter sido inspirada e concretizada a partir da experiência de socialização em família relatada pela jovem pesquisadora gonçalense Paola Machado de Oliveira sobre as relações intra familiares locais entre pais, irmãos mais velhos e irmãos mais novos.

${ }^{3} \mathrm{GOHN}$ (2008, p.102) , ao diferenciar métodos e procedimentos não formais em educação de procedimentos escolares formais e procedimentos informais em educação, utiliza a expressão "sequência cronológica diferencial" para se referir a fixação e ao uso do tempo de aprendizagem de acordo com ações de cunho cultural e educacional, além de político.

${ }^{4}$ Fayga Ostrower, polonesa de nascimento, chegou ainda adolescente ao Brasil na década de 30, e faleceu em 2001 aos 81 anos. Foi gravadora, pintora, desenhista, ilustradora, teórica da arte e professora, tendo lecionado no Museu de Arte Moderna entre 1954 -70; em várias universidades no exterior e no Brasil ( em pós-graduação principalmente). Sua área de ensino compreendeu a teoria da arte, sobretudo os princípios básicos da linguagem visual, a estrutura do espaço relacionada à expressividade das formas e o papel da percepção e da intuição nos processos criativos. Para a autora , as múltiplas linguagens artísticas e não artísticas, verbais e não verbais moldam-se numa linguagem comum: nas vivências do espaço. Nesta experiência fundamental se desenvolvem a consciência, a percepção e a autopercepção das pessoas, assim como seu senso de identidade.

${ }^{5}$ Este artigo aborda a relação entre o território e a memória, tendo a violência na Colômbia ( até 2007) como pano de fundo. Parte da revisão destes conceitos a partir da teoria social com aportes da antropologia audiovisual. Apresenta alguns caminhos metodológicos e debate a aprendizagem obtida a partir de exercícios de reconstrução da memória, descobrindo tanto sua potência ética como as possibilidades abertas pela interação entre a etnografia e o trabalho audiovisual para a gestação de um efetivo diálogo entre saberes e a construção conjunta de conhecimento.

\section{Bibliografia}

ARANGO, V.M. y RENDÓN, G. A. Territórios visuales del tiempo y la memória. Exploraciones metodológicas en la vereda Mogotes, Buriticá, Antioquia. Boletín de Antropologia, volume 22, no 39, 2008. Medellín: Universidad de Antioquia. 
COSTA, L.M. de C. Mapas como expressão da dinâmica social: um levantamento em artigos acadêmicos, 101p. Monografia em Geografia. IGEO / UFRJ, 2003.

GOHN, Maria da Glória Marcondes. Educação não formal e cultura política: impactos sobre o associativismo do terceiro setor. 4를 edição. São Paulo: Editora Cortez, 2008

OSTROWER, Fayga. Acasos e criação artística. Rio de Janeiro: Editora Campus, 1990.

PONTUSCHKA, N., PAGANELLI, T. e CACETE, N. Para ensinar e aprender Geografia. São Paulo: Cortez, 2007.

RIBEIRO, A.C.T. Sociabilidade hoje; leitura da experiência urbana. Caderno CRH, Salvador, vol. 18, no 45, p. 411 - 422 set. / dez. 2005.

RIBEIRO, A.C.T. Vínculo social: cartografia da ação em contextos metropolitanos. Projeto de pesquisa. Rio de Janeiro: LASTRO-IPPUR/UFRJ, CNPq/FAPERJ, 2007.

SANTOS, B. de S. Uma cartografia simbólica das representações sociais: prolegômenos a uma concepção pós-moderna do direito. Revista Espaço e Debates. São Paulo, № 33 1991.

SANTOS, Milton. Técnica espaço tempo. Globalização e meio técnico científico informacional. São Paulo: ed. HUCITEC, 1994.

SANTOS, M. O território e o saber local: algumas categorias de análise. Cadernos IPPUR, Rio de Janeiro, ano XIII, № 2, 1999, p. 15-26 